\title{
Global Journal of Engineering and Technology Advances
}

eISSN: 2582-5003

Cross Ref DOI: $10.30574 /$ gjeta

GJETA

Journal homepage: https://gjeta.com/

(RESEARCH ARTiCLE)

Check for updates

\section{Using Atmega 16 for pressure measuring instrumentation for industrial applications}

\section{HS Bui * and DC Nguyen}

Université de Technologie de Ha Noi-Ha Noi, 10000, Viet Nam.

Global Journal of Engineering and Technology Advances, 2021, 08(02), 017-022

Publication history: Received on 15 June 2021; revised on 17 July 2021; accepted on 20 July 2021

Article DOI: https://doi.org/10.30574/gjeta.2021.8.2.0106

\begin{abstract}
Pressure measurement plays an extremely important role in the industrial domain such as hydraulics, pneumatics or steam pressure, in water filtration system. Measurement and monitoring need to be continuous and in time in order to adjust and control that will avoid excess permissive pressure, damage to pipes, tanks and equipment, and even cause explosion and damage to equipment, facilities and the environment. Pressure measurement is also used in automobiles, ships, machinery and equipment in the construction industry, transporting materials.
\end{abstract}

A pressure gauges using Atmega 16 sensor will be used in order to observe and store the whole process for satisfying the demands. This instrumentation can be designed and integrated completely.

Keywords: Atmega 16; Eectronic instrumentation; Pressure gauges

\section{Introduction}

In fact, most of the pressure gauges used today are mechanical, so the measurement results must go to the installation site for monitoring. Therefore, it is very difficult and it is not possible to look up the history of the measuring device or improve ability to measure of instrumentation (Figure 1).

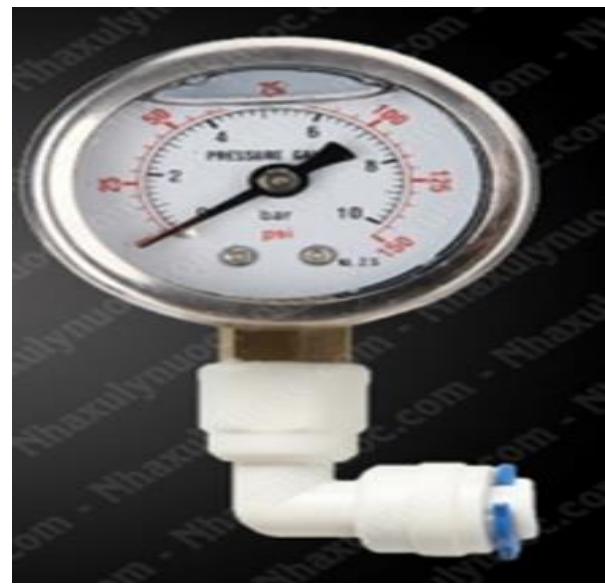

Figure 1 Mechanical pressure measuring instrumentation

\footnotetext{
${ }^{*}$ Corresponding author: HS Bui

Université de Technologie de Ha Noi -Ha Noi, 10000, Viet Nam.
}

Copyright $(2021$ Author(s) retain the copyright of this article. This article is published under the terms of the Creative Commons Attribution Liscense 4.0 . 
Writing embedded programs for microcontrollers and creating a webserver as a database to store as well as transmit information, monitor measured pressure parameters.

\section{General design theory}

There are many different types of sensors as well as components using for measured pressure parameters. The schematic diagram of the system for measuring pressure will be designed and make printed circuit board, then manufacturing the hardware related to the product.

The system will include 2 different electronic circuit parts, transmitting and receiving information with each other by RF waves. It consists of one central circuit and another sensor circuits. The sensor circuit has the function of measuring pressure, processing the pressure signal and transmitting it to the central circuit.

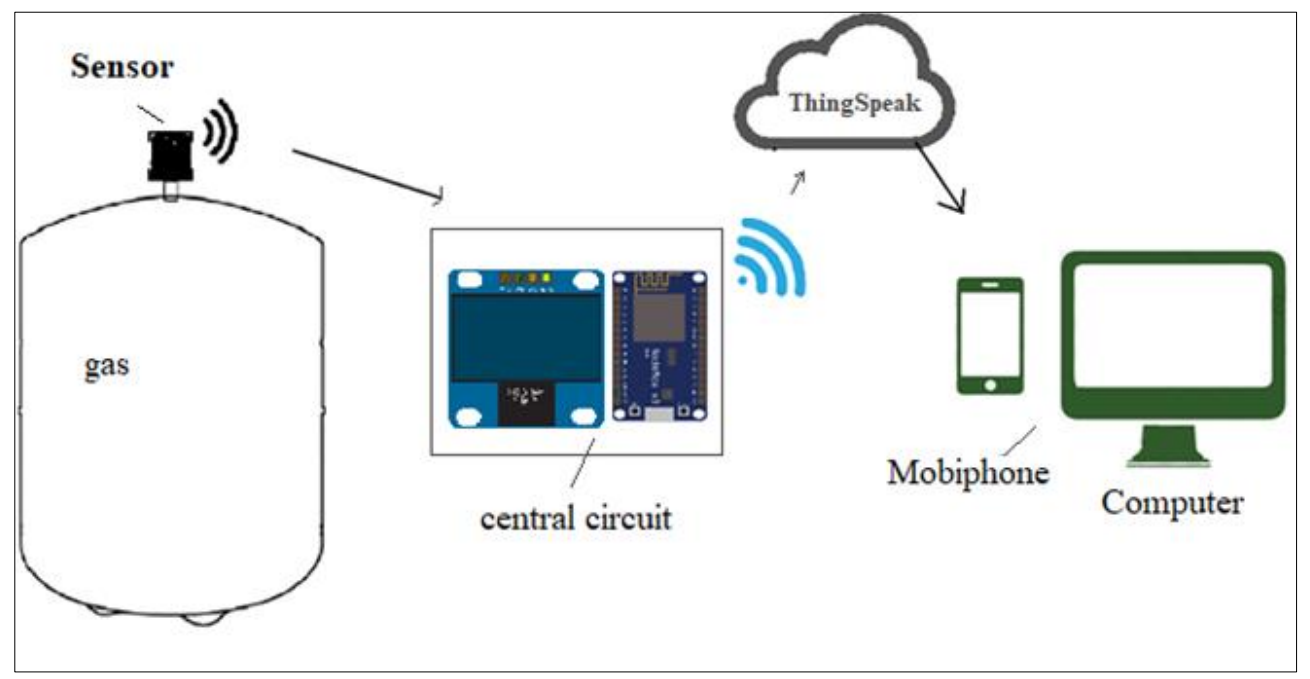

Figure 2 Diagram of pressure measuring system

The central circuit (figure 3) is the circuit that has the function of receiving the sent information of the sensor circuit and then displaying it directly on the OLED screen, web interface and phone, warning if the limit is exceeded.

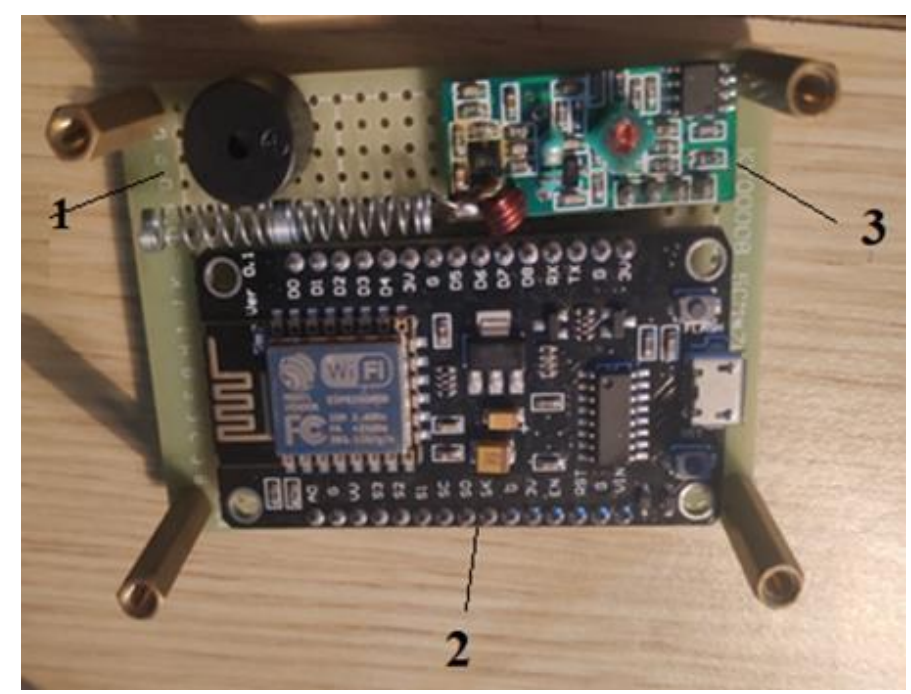

Figure 3 The central circuit blocks

1. Horne 2. Board Node MCU ESP8266 3. RF Receiver Module

The central circuit does not require too much compactness and size, so the board is assembled in a modular way, so that, it will be easy to choose for connecting components, easy to replace and upgrade. 
The schematic diagram of the pressure measurement circuit using Atmega 328p is described in the figure 4 as bellow:

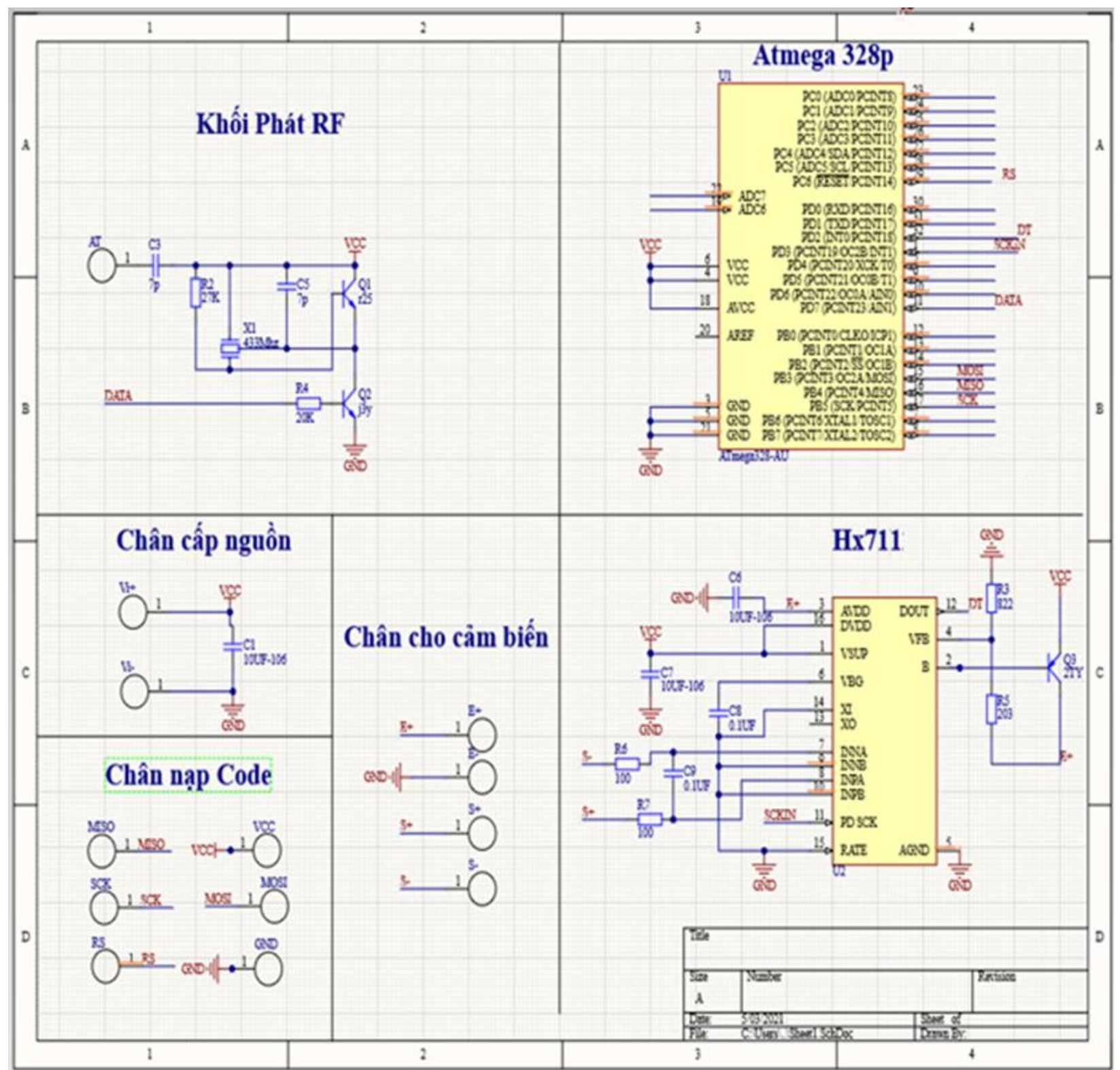

Figure 4 Schematic diagram of the pressure measurement circuit using Atmega 328p

In order for the Printed Circuit Board to be optimized in terms of size, each block will be placed as close to each other as possible and separately into each cluster.

The top of the Printed Circuit Board is the Radio frequency blocks, the microcontroller, the feed and power pins. Includes components as shown in Figure 5.

The figure 6 is the pressure measuring instrumentation product. It has 2 main parts, the main part (figure 6a) includes an antenna, a screen, a button and a knob. Here the knob and push button will be used to set the alarm level for the device. The sensor's exterior (figure $6 \mathrm{~b}$ ) includes an antenna, a switch to select battery mode, a power jack, and a highpressure intake.

Write embedded programs for microcontrollers and create a webserver as a database to store as well as transmit information, monitor measured pressure parameters. The final step is testing, evaluating the accuracy of the system and recalibrating the software and hardware so that the results obtained are as small as possible. 


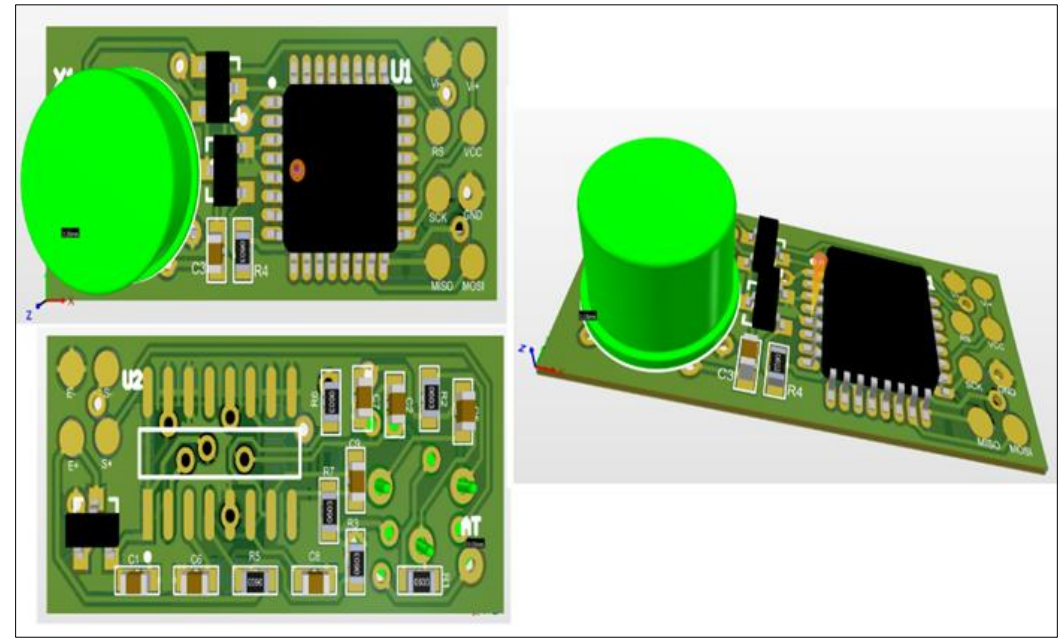

Figure 5 The 3D image of the pressure sensor circuit

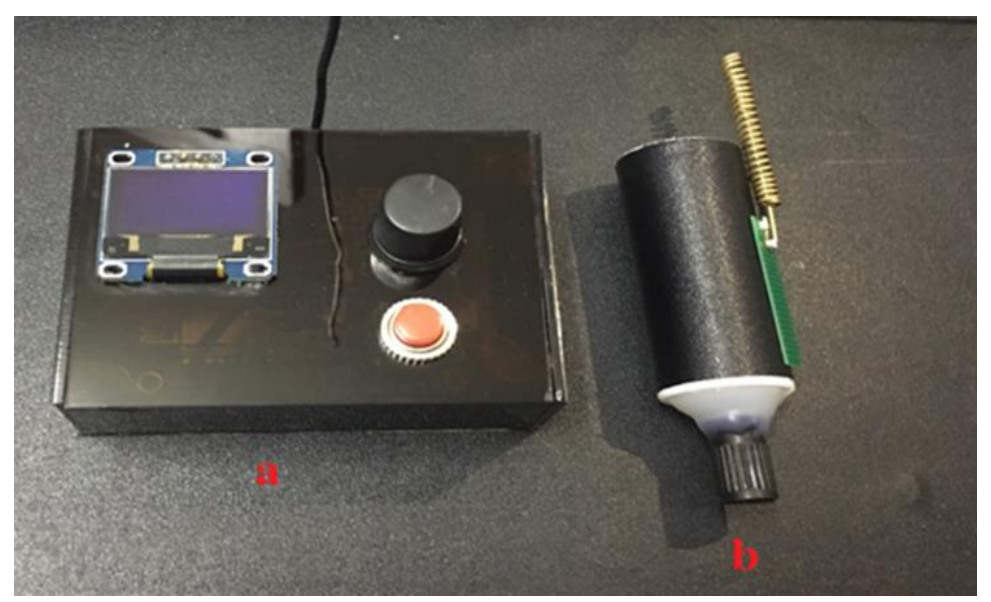

Figure 6 Pressure measuring instrumentation
a. Main part
b. Sensor's exterior part

\section{Creating Thing Speak Web sever}

ThingSpeak is an open-source Internet of Things (IoT) application for storing and retrieving data using HTTP protocols over the Internet or over a Local Area Network. ThingSpeak allows creating sensor applications, logging, location tracking applications and sensor networks with status updates to the server, we will get the result as shown in Figure 7.

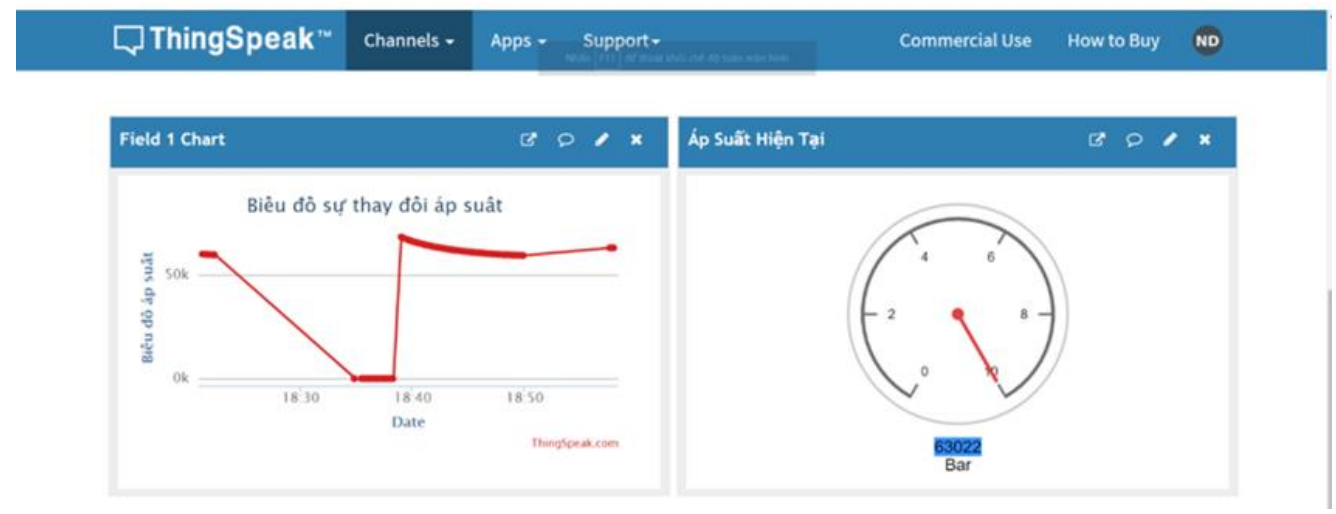

Figure 7 Measured pressure data has been sent to Thing speak 
Furthermore, the measurement results can be displayed on the mobile phone. The mobile interface is very friendly and full of necessary values we want to use. On the interface, we can also set alarms for the cases of maximum pressure (for example 2,83 Bar) or minimum pressure (for example 1,25 Bar) values. This will help users easily recognize and make early decisions even though they are far from the measuring device.

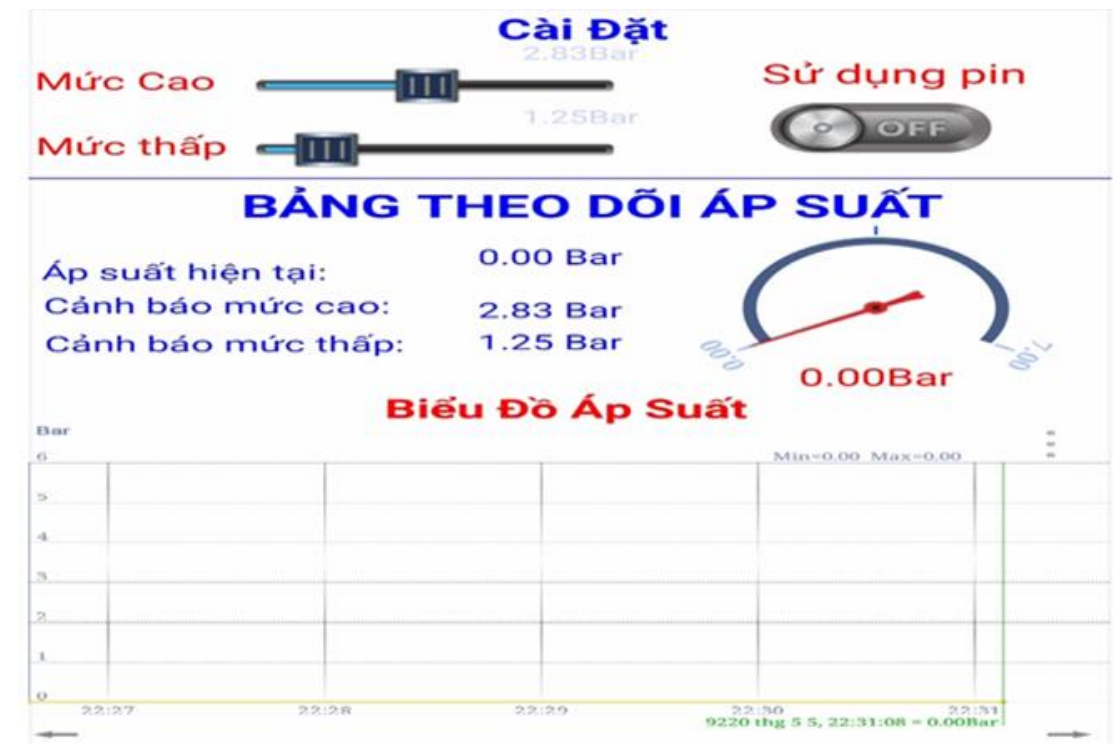

Figure 8 The interface displayed on the phone

\section{Experimental results}

We do an experiment with the newly built device and compare it with 2 control devices, a mechanical measuring device and an electronic device (figure 9). From there know the error of the measurement and correct it. We adjust the measuring range of the device we have just built in the range of 1-7 Bar and perform experiments in this range when compared with the 2 reciprocating devices.

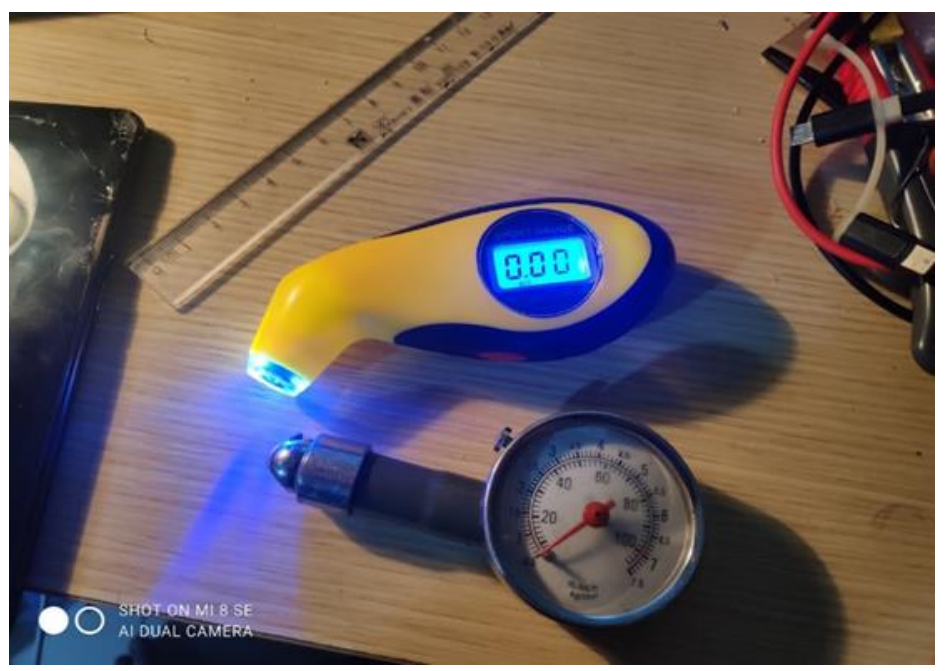

Figure 9 Mechanical and Electronic pressure measuring instrumentation

The measurement results from the newly designed pressure measuring instrumentation and the pressure gauges currently in use give us the results as shown in the following table.

Comparing the measured results shows that the error of the devices is not much and less than $3.6 \%$. So, we can temporarily accept this result and will have more detailed and accurate studies by comparing with standard measuring instruments to properly calibrate the designed pressure measuring instrumentation. 
Table 1 Table of test results

\begin{tabular}{|c|c|c|c|}
\hline No & Pressure measured by new device (Bar) & Pressure measured by gauges (Bar) & Error (\%) \\
\hline 1 & 3.25 & 3.3 & 1.5 \\
\hline 2 & 2.17 & 2.2 & 1.3 \\
\hline 3 & 1.5 & 1.5 & 0 \\
\hline 4 & 1.2 & 1.22 & 1.6 \\
\hline 5 & 1.06 & 1.1 & 3.6 \\
\hline
\end{tabular}

\section{Conclusion}

The study of the pressure is one of the most important aspects for many domains. The importance of this research is to design and manufacture low-cost acquisition systems with increased efficiency. According to the analysis and description in this paper, the integration to produce a complete pressure measuring instrumentation to meet the requirements of screening and threshold warning while working ensuring safety standards are very possible and necessary.

Further research also is needed to compare with standard measuring instruments and find more accurate sensors, design and manufacture even more smaller equipment to be able to apply to more industries in reality.

\section{Compliance with ethical standards}

\section{Acknowledgments}

This work has been supported/partly supported by VNU University of Engineering and Technology under project number CN20.13.

\section{Disclosure of conflict of interest}

No conflict of interest.

\section{References}

[1] Phạm Mạnh Thắng, Hoàng Văn Mạnh, Vi xử lý và Vi điều khiển: Nguyên lý và ứng dụng, Nhà Xuất Bản Đại Học Quốc Gia Hà Nội. 2016.

[2] Lê Văn Doanh, Các Bộ Cảm Biến Trong Kỹ Thuật Đo Lường Và Điều Khiển, Nhà xuất bản khoa học và kỹ thuật, Hà Nội. 2005.

[3] Hoàng Minh Công, Giáo trình cảm biến công nghiệp, Đại học Bách Khoa Đà Nẵng, Đà Nẵng. 2004.

[4] Jon S. Wilson, Sensor Technology Handbook.

[5] Available from https://www.arduino.cc/

[6] Available from https://thingspeak.com/

[7] DC Nguyen, Research and application of pressure measuring instrumentation in industrial, June 2021.

[8] Available from http://www.letsmakerobot.ru/category/radioismfsk/.

[9] Available from http://domoticx.com/atmega328-au-programmeren-met-arduino-als-isp/ 